\title{
Distribution of polycyclic aromatic hydrocarbons (PAHs) in rivers and estuaries in Malaysia: a widespread input of petrogenic PAHs
}

\begin{abstract}
This is the first publication on the distribution and sources of polycyclic aromatic hydrocarbons (PAHs) in riverine and coastal sediments in South East Asia where the rapid transfer of land-based pollutants into aquatic environments by heavy rainfall and runoff waters is of great concern. Twenty-nine Malaysian riverine and coastal sediments were analyzed for PAHs (3ī 7 rings) by gas chromatography mass spectrometry. Total PAHs concentra tions in the sediment ranged from 4 to $924 \mathrm{ng} / \mathrm{g}$. Alkylated homologues were abundant for all sediment samples. The ratio of the sum of methylphenanthrenes to phenanthrene (MP/P), an index of petrogenic PAHs contribution, was more than unity for 26 sediment samples and more than 3 for seven samples for urban rivers covering a broad range of locations. The MP/P ratio showed a strong correlation with the total PAHs concentrations, with an $\mathrm{r} 2$ value of 0.74 . This ratio and all other compositional features indicated that Malaysian urban sediments are heavily impacted by petrogenic PAHs. This finding is in contrast to other studies reported in many industrialized countries where PAHs are mostly of pyrogenic origin. The MP/P ratio was also significantly correlated with higher molecular weight PAHs such as benzo[a]pyrene, suggesting unique PAHs source in Malaysia which contains both petrogenic PAHs and pyrogenic PAHs. PAHs and hopanes fingerprints indicated that used crankcase oil is one of the major contributors of the sedimentary PAHs. Two major routes of inputs to aquatic environments have been identified:प(1) spillage and dumping of waste crankcase oil and (2) leakage of crankcase oils from vehicles onto road surfaces, with the subsequent washout by street runoff. N-Cyclohexyl-2-benzothiazolamine (NCBA), a molecular marker of street dust, was detected in the polluted sediments. NCBA and other biomarker profiles confirmed our hypothesis of the input from street dust contained the leaked crankcase oil. The fingerprints excluded crude oil, fresh lubricating oil, asphalt, and tire-particles as major contributors.
\end{abstract}

Keyword: Polycyclic aromatic hydrocarbons (PAHs); Riverine; Coastal sediments; Water pollutant 